\title{
Produção de tomateiro orgânico irrigado por aspersão e gotejamento, em cultivo solteiro e consorciado com coentro
}

\author{
Waldir A Marouelli ${ }^{1,4}$; Maria A de Medeiros ${ }^{2}$; Rodrigo F de Souza ${ }^{3}$; Francisco V Resende ${ }^{1}$

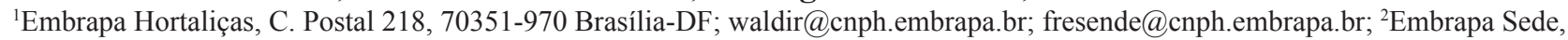 \\ Parque Estação Biológica s/nº 70770-901 Brasília-DF; maria.alice@embrapa.br; ${ }^{3}$ UnB, C. Postal 4508, $70910-970$ Brasília-DF; \\ rodriggofernandes2@hotmail.com
}

\section{RESUMO}

O uso eficiente da água e a diversificação ambiental são fundamentais para o equilíbrio e a sustentabilidade dos sistemas orgânicos de produção de tomate. O presente estudo teve por objetivo avaliar a produção de tomate de mesa em cultivo solteiro e consorciado com coentro com irrigação por aspersão e gotejamento, em sistema orgânico. $\mathrm{O}$ experimento foi conduzido em área de produção orgânica no Distrito Federal. O delineamento foi blocos ao acaso, com tratamentos dispostos num arranjo fatorial 2 × 2 (dois sistemas de irrigação $\mathrm{x}$ dois sistemas de cultivo). Não houve interação significativa entre os fatores avaliados, assim como não houve efeito do sistema de cultivo sobre as variáveis avaliadas. Embora o ciclo do tomateiro irrigado por gotejamento tenha diminuído, a produtividade de frutos não foi afetada pelos sistemas de irrigação. A maior redução de estande verificada na aspersão foi compensada por um aumento no número de frutos por planta, sem variação na massa por fruto. O menor volume de solo explorado pelas raízes do tomateiro associado à maior incidência de traça-do-tomateiro (Tuta absoluta) e principalmente de oídio (Leveillula taurica) pode ter limitado a produtividade do tomateiro irrigado por gotejamento. A taxa de frutos podres na aspersão foi o dobro da verificada no sistema por gotejamento.

Palavras-chave: Solanum lycopersicon, Coriandrum sativum, agricultura orgânica, tomate de mesa.

\begin{abstract}
Production of organic tomatoes irrigated by sprinkler and drip systems, as single crop and intercropped with coriander

The efficient use of water and the environmental diversity are crucial to the balance and sustainability of the organic production system of tomatoes. The present study aimed to evaluate the organic production of tomato cultivated as a single crop and in consortium with coriander, under sprinkler and drip irrigation. The experiment was carried out at an organic production area on the Federal District of Brazil. The experimental design was randomized blocks with treatments arranged in a $2 \times 2$ factorial (two irrigation systems $\mathrm{x}$ two cropping schemes). No significant interaction between the both factors occurred, and there was no significant effect of the cropping scheme over the evaluated variables. Although the crop cycle has been reduced when tomato was drip irrigated, the fruit yield was not affected by the irrigation systems. The larger reduction in the stand of plants observed under sprinkler irrigation has been compensated by an increase in the number of fruits per plant, without a change on the fruit mass. The smaller volume of soil explored by the tomato roots associated with the higher incidence of South American tomato pinworm (Tuta absoluta) and mainly powdery mildew (Leveillula taurica) may have limited the yield of drip irrigated tomato. The fruit decay rate on sprinkle irrigated plants was twice the rate found on the drip irrigated system.
\end{abstract}

Keywords: Solanum lycopersicon, Coriandrum sativum, organic agriculture, fresh-market tomato.

(Recebido para publicação em 29 de janeiro de 2010; aceito em 11 de julho de 2011)

(Received on January 29, 2010; accepted on July 11, 2011)

\begin{abstract}
$\mathrm{A}$ busca por alimentos saudáveis e livres de contaminação por agrotóxicos tem crescido mundialmente, sendo que o mercado de orgânicos no Brasil cresce a uma taxa acima de $30 \%$ ao ano (Tamisio, 2005). Dentre as hortaliças, o tomate (Solanum lycopersicon) é uma das mais procuradas, pois é uma das culturas com maior uso de produtos fitossanitários no sistema de produção convencional. No entanto, existe grande dificuldade de cultivo do tomateiro em sistemas orgânicos devido aos problemas fitossanitários que a cultura apresenta (Souza, 2003; Schallenberger
\end{abstract}

et al., 2008), sendo este um dos fatores que torna o custo do tomate orgânico mais alto que o convencional.

O uso eficiente dos recursos naturais nos sistemas orgânicos de produção é fundamental para alcançar o equilíbrio ecológico e a sustentabilidade do sistema produtivo. Dentre os recursos naturais, a água é provavelmente o mais vital para o cultivo de tomate, que é normalmente produzido com irrigação. Além de suprir as necessidades hídricas das plantas, a água também proporciona a solubilização e a disponibilização dos nutrientes do solo.
Cultivos de tomateiro submetidos a condições de falta ou excesso de água têm a produtividade e a qualidade de frutos comprometidas (Pulupol et al., 1996; Marouelli \& Silva, 2007) e são mais suscetíveis à incidência de doenças e ao ataque de insetos-pragas (Lopes et al., 2006). Existe uma estreita relação entre o aparecimento e o desenvolvimento de algumas doenças no tomateiro e a forma com que a água é aplicada às plantas. As condições que favorecem a maioria das doenças das plantas são a existência de água livre na folha e o alto teor de água no solo (Rotem \& Palti, 
1969; Marouelli et al., 2005). Assim, a irrigação por aspersão pode acentuar a sobrevivência e a dispersão de vários patógenos em razão da água ser aplicada sobre a parte aérea das plantas. Por outro lado, o impacto das gotas de água pode agir na remoção de propágulos de alguns patógenos, como o oídio Oidium lycopersici e Oidiopsis sicula (Erysiphaceae), e no desalojamento de esporos fúngicos e de células bacterianas (Lopes et al., 2006).

Os sistemas de irrigação por sulco e por gotejamento minimizam a incidência de várias doenças bacterianas foliares em tomateiro, por não molharem a parte aérea das plantas, mas favorecem as doenças causadas por patógenos de solo, especialmente em condições de drenagem deficiente (Marouelli et al., 2005; Lopes et al., 2006). Apesar de o gotejamento ser destacadamente o sistema de irrigação que possibilita maiores produtividades de frutos, o sistema por sulco é ainda um dos mais adotados no Brasil na produção convencional de tomate de mesa, principalmente devido ao seu baixo custo de implantação (Coletti \& Testezlaf, 2003).

Ao contrário da maioria dos produtores convencionais de tomate tutorado, a aspersão é, possivelmente, o método de irrigação mais utilizado por produtores orgânicos de tomate (Menezes et al., 2007). Isso ocorre especialmente como forma de controlar alguns insetos-pragas e doenças (Costa et al., 1998; Coelho et al., 2000). A aspersão pode reduzir a população de ácaros e de insetos-pragas, tais como a traça-do-tomateiro Tuta absoluta e alguns insetos vetores de viroses, devido ao impacto das gotas na remoção de ovos, larvas e pupas (Costa et al., 1998; Lopes et al., 2006).

Em sistemas orgânicos de produção, a diversificação ambiental é fundamental para alcançar o equilíbrio do sistema produtivo. Desta forma, consórcios, barreiras e corredores de vegetação funcionam como recursos alternativos para a manutenção dos inimigos naturais, promovendo a manutenção de insetos herbívoros frequentemente em níveis aceitáveis (Altieri et al., 2003). Trabalhos recentes mostram que o cultivo de coentro (Coriandrum sativum) em consórcio com tomateiro teve in- fluência no crescimento populacional da mosca-branca Bemisia tabaci e da traça-do-tomateiro (Medeiros et al., 2009; Togni et al., 2009), representando uma alternativa para minimizar os danos causados por estes insetos em sistemas orgânicos de produção.

De acordo com Medeiros et al. (2009), o coentro é uma boa escolha para diversificar o sistema de cultivo do tomateiro, porque apresenta baixo grau de competição com a cultura alvo e pode incrementar os inimigos naturais no cultivo. Além da vantagem da diversificação ambiental, no que se refere a problemas fitossanitários, o consórcio do tomateiro com outras plantas é uma alternativa que pode possibilitar ao produtor uma renda extra (Souza, 2003).

O objetivo do presente estudo foi avaliar a produção de tomate de mesa em cultivo solteiro e consorciado com coentro, com irrigação por aspersão e gotejamento, conduzido em sistema orgânico de produção no Distrito Federal.

\section{MATERIAL E MÉTODOS}

O estudo foi conduzido de julho a novembro de 2008, no Campo Experimental da Embrapa Hortaliças, Distrito Federal ( $15^{\circ} 56^{\prime} \mathrm{S}, 48^{\circ} 08^{\prime} \mathrm{W}$, altitude $997 \mathrm{~m}$ ). O solo é classificado como Latossolo Vermelho distrófico típico, fase cerrado e com textura argilosa. O clima da região é do tipo $\mathrm{Cwa}$, segundo a classificação de Köppen (temperado úmido com inverno seco e verão quente).

Avaliaram-se os fatores sistema de irrigação (aspersão e gotejamento) e sistema de cultivo (tomateiro solteiro e consorciado com coentro), ou seja, quatro tratamentos: 1) tomateiro em cultivo solteiro irrigado por aspersão; 2) tomateiro consorciado com coentro irrigado por aspersão; 3) tomateiro em cultivo solteiro irrigado por gotejamento; e 4) tomateiro consorciado com coentro irrigado por gotejamento.

Antes da instalação do experimento a área foi cultivada com crotalária (Crotalaria juncea) para fins de adubação verde, sendo incorporada ao terreno cerca de 30 dias antes da semeadura do coentro. Ao redor do experimento foram estabelecidas bordaduras de milho
(Zea mays) e sorgo forrageiro (Sorghum bicolor) como barreira de vento e para aumentar a diversidade vegetal no sistema produtivo. Adicionalmente, as curvas de nível laterais à área experimental foram mantidas com barreiras fixas de quebra-ventos compostas por faixas de girassol mexicano (Tithonia diversifolia) e capim-elefante (Pennisettum purpureum).

O transplante das mudas de tomateiro (cultivar Poliana) foi realizado no sistema de fileiras duplas, espaçadas de $1,6 \times 0,8 \mathrm{~m}$, com $0,5 \mathrm{~m}$ entre plantas ao longo das fileiras. A parcela experimental foi composta de cinco fileiras duplas de plantas com $10 \mathrm{~m}$ de comprimento, com área total de $120 \mathrm{~m}^{2}(10 \times 12 \mathrm{~m})$. Da parcela experimental foram avaliadas as plantas existentes em 7,5 $\mathrm{m}$ de cada uma das três fileiras duplas centrais, com área útil de $54 \mathrm{~m}^{2}$ (7,5 x 7,2 m). Cada tratamento foi reproduzido três vezes, totalizando doze parcelas experimentais.

Nos tratamentos de cultivo consorciado, o coentro foi semeado ao longo da fileira de tomateiros 15 dias antes do transplante de mudas. O coentro foi colhido aos 55 dias, deixando para florescer uma planta de coentro entre duas plantas de tomateiro. Posteriormente, foi ressemeado e colhido, mantendo-se outra planta de coentro para florescer entre duas de tomateiro.

Em adubação de pré-plantio foram aplicados e incorporados, em cada metro linear de fileira "simples" de plantas, $200 \mathrm{~g}$ de termofosfato e $2,0 \mathrm{~kg}$ de composto orgânico feito com cama de matrizes de aviário, conforme o padrão de adubação para o sistema orgânico de produção de tomate adotado na Embrapa Hortaliças (Couto et al., 2008). A adubação em cobertura foi feita aos 55 dias após o transplante, aplicando-se 250 g por planta do mesmo composto orgânico.

As plantas de tomate foram tutoradas na vertical, com o uso de fitilho, e conduzidas com uma haste, sendo podadas com 1,7 m de altura. Na segunda metade do ciclo do tomateiro foram realizadas duas aplicações de calda bordalesa e duas de bioinseticida a base de Bacillus thuringiensis, devido às condições climáticas favoráveis à incidência de doenças e à infestação de traça-do- 
-tomateiro em todos os tratamentos. Foram eliminadas da área experimental as plantas de tomateiro mortas ou improdutivas devido a problemas de viroses, especialmente as causadas por espécies de vírus dos gêneros Tospovirus ("vira-cabeça") e Begomovirus (geminivírus).

Nos tratamentos irrigados por aspersão foram utilizados aspersores de impacto com bocais de $5 \times 8 \mathrm{~mm}$, pressão de serviço de $2,5 \mathrm{kgf} \mathrm{cm}^{-2}$, espaçados de 18 x 12 m e intensidade de aplicação de $23,5 \mathrm{~mm} \mathrm{~h}^{-1}$. Os aspersores foram instalados a 1,8 m de altura. Nos tratamentos irrigados por gotejamento foram usados tubos gotejadores, instalando-se uma linha de gotejadores por fileira simples de plantas, com emissores espaçados de $0,2 \mathrm{~m}$ entre si, pressão de serviço de 1,0 kgf $\mathrm{cm}^{-2}$ e vazão de $1,6 \mathrm{~L} \mathrm{~h}^{-1}$.

O manejo de irrigação foi realizado de forma individualizada por tratamento de irrigação. Tensiômetros foram instalados em todas as parcelas experimentais ao longo da linha de plantio, a cerca de $10 \mathrm{~cm}$ da planta e do gotejador, e a $50 \%$ da profundidade efetiva do sistema radicular. Como tal profundidade varia ao longo do ciclo do tomateiro, a cápsula dos tensiômetros ficou a $10 \mathrm{~cm}$ de profundidade durante o estádio vegetativo, a $15 \mathrm{~cm}$ até cerca de duas semanas antes da primeira colheita e a $20 \mathrm{~cm}$ a partir da primeira colheita. As parcelas foram irrigadas sempre que a média de tensão de água no solo atingia valores entre 25 kPa e 40 kPa (Marouelli \& Calbo, 2009). Assim, as irrigações nos tratamentos com e sem coentro, para um mesmo sistema de irrigação, foram realizadas no mesmo dia e com a mesma lâmina de água. O limite inferior de tensão de água no solo foi utilizado durante o estádio de frutificação, no qual o tomateiro é mais sensível ao déficit de água no solo (Marouelli \& Silva, 2007).

A lâmina de água aplicada por irrigação foi suficiente para que o solo retornasse a condição de capacidade de campo na profundidade radicular efetiva, sendo que para os tratamentos irrigados por gotejamento foi considerado um fator de $60 \%$ de área molhada. A eficiência de irrigação foi estimada em $80 \%$ na aspersão e $85 \%$ para o gotejamento.

Os frutos foram colhidos semanal- mente no estádio verde-maduro. Foram avaliadas as variáveis estande final, produtividade total e comercializável; quantidade total e comercializável de frutos por unidade de área e por planta; massa de fruto comercializável, taxa de frutos podres, com danos por traça-do-tomateiro e por broca grande (Helicoverpa zea) e severidade de oídio, causado pelo fungo Leveillula taurica. Diferentemente do tomateiro, nenhuma variável associada à produção de coentro foi avaliada.

Os frutos considerados comercializáveis foram aqueles com diâmetro acima de $40 \mathrm{~mm}$ e sem defeitos graves (Brasil, 1995). Frutos com podridão, queimadura, defeitos fisiológicos e/ou lesões de ordem mecânica ou causadas por insetos maiores que $1,5 \mathrm{~mm}$ foram considerados como não comercializáveis.

A severidade do ódio foi avaliada aos 90 dias após o transplante das mudas, quando a doença havia atingido alta intensidade. As avaliações foram feitas no terço inferior de oito plantas escolhidas ao acaso nas duas fileiras centrais das parcelas experimentais, utilizando-se a seguinte escala de notas: 0 para folhas sem sintomas; 1 para folhas com até 10 lesões amareladas; 2 para folhas com 10 a 50 lesões; 3 para folhas com mais de 50 lesões, 4 para folhas secas; e 5 para planta morta.

Para análise de variância dos dados das variáveis acima foi utilizado o delineamento experimental de blocos ao acaso, em esquema fatorial $2 \times 2$, considerando $p=0,05$ como limite máximo de significância.

Avaliou-se também a quantidade total de irrigações realizadas, a lâmina de irrigação aplicada e o crescimento do sistema radicular do tomateiro nos diferentes tratamentos de irrigação. A lâmina de água aplicada via irrigação foi determinada com base na média das lâminas obtidas em três coletores instalados entre duas fileiras duplas de planta, na diagonal de duas parcelas experimentais de cada tratamento irrigado por aspersão. Nos tratamentos com gotejamento, a lâmina foi calculada com base no tempo de irrigação e na média das vazões de quarenta gotejadores, avaliadas no início e no final do experimento em quatro parcelas. Dados climáticos no período de condução do tomateiro foram obtidos na Estação Agroclimatológica da Embrapa Hortaliças, a 600 m da área experimental.

A distribuição do sistema radicular do tomateiro no perfil do solo, nos tratamentos irrigados por aspersão e gotejamento, foi determinada pelo método do perfil reticulado (Atkinson \& Mackie-Dawson, 1991) em uma das parcelas experimentais de cada tratamento. Foi aberta uma trincheira de 90 $\mathrm{cm}$ de profundidade perpendicularmente a uma fileira dupla central de plantas. A concentração de raízes, dentro de cada malha de $10 \times 10 \mathrm{~cm}$, foi avaliada utilizando-se notas de " 0 " (ausência de raízes) a "5" (máxima concentração), do lado externo fileira dupla de plantas.

\section{RESULTADOS E DISCUSSÃO}

O ciclo de desenvolvimento do tomateiro irrigado por aspersão foi de 122 dias, enquanto no gotejamento foi de 115 dias, independente do sistema de cultivo. Foram realizadas sete colheitas nos tratamentos com aspersão e seis nos com gotejamento. Produtores orgânicos de tomate do Distrito Federal têm conseguido entre quatro e cinco colheitas, em condições de campo.

Nos tratamentos irrigados por aspersão foram feitas 29 irrigações ao longo do ciclo do tomateiro, oito a menos que nos tratamentos com gotejamento. A maior quantidade de regas no gotejamento se deve, sobretudo, ao menor volume de solo molhado, uma vez que a faixa de tensão-limite de água no solo para se irrigar foi igual em ambos os sistemas de irrigação.

A lâmina total bruta de água aplicada ao longo do ciclo do tomateiro irrigado por aspersão totalizou 673 $\mathrm{mm}$, enquanto no gotejamento foi de $542 \mathrm{~mm}$, que representa uma redução de $20 \%$ no volume de água fornecido via gotejamento. A precipitação total foi de $83 \mathrm{~mm}$ nos tratamentos irrigados por aspersão e de $26 \mathrm{~mm}$ nos tratamentos com gotejamento. Tal diferença se deve a $57 \mathrm{~mm}$ de chuva terem ocorrido após a última colheita do tomateiro irrigado por gotejamento, quando as plantas irrigadas por aspersão ainda estavam 
Tabela 1. Valores médios de redução de estande (\%), produtividade total e de frutos comercializável ( $\mathrm{t}$ ha $\left.{ }^{-1}\right)$, número de frutos totais e comercializáveis por unidade de área e por planta, massa de frutos comercializáveis (g), frutos podres, com danos por traça-do-tomateiro e por broca grande (\% em número), e severidade de oídio, conforme o sistema de irrigação, e nível de probabilidade do teste $\mathrm{F}$ (average values of stand reduction, total and marketable yield $\left(\mathrm{t} \mathrm{ha}^{-1}\right)$, total and marketable number of fruits per unit area and per plant, marketable fruit weight, fruit damage by South American tomato pinworm and Southern armyworm, and severity of powdery mildew, depending on the irrigation system and cropping schemes, and probability level of F test). Brasília, Embrapa Hortaliças, 2008.

\begin{tabular}{|c|c|c|c|c|c|c|c|c|c|c|c|c|}
\hline \multirow[t]{2}{*}{ Sistema } & \multirow{2}{*}{$\begin{array}{c}\text { Estande } \\
(\%)\end{array}$} & \multicolumn{2}{|c|}{ Produtividade (t/ha) } & \multicolumn{2}{|c|}{ Frutos totais } & \multicolumn{3}{|c|}{$\begin{array}{c}\text { Frutos } \\
\text { comercializáveis }\end{array}$} & \multicolumn{3}{|c|}{$\begin{array}{c}\text { Frutos } \\
\text { com danos }\end{array}$} & \multirow[t]{2}{*}{ Oídio } \\
\hline & & Total & Comercial & $\mathbf{m}^{2}$ & $\overline{\text { Planta }}$ & $\mathbf{m}^{2}$ & Planta & Massa & Podre & Traça & Broca & \\
\hline Gotejo & 16,1 & 58,8 & 39,3 & 42,6 & 27,3 & 24,3 & 15,6 & 161 & 4,8 & 47,4 & 10,4 & 4,5 \\
\hline Aspersão & 33,9 & 64,8 & 42,9 & 45,7 & 32,6 & 25,2 & 18,0 & 163 & 9,6 & 42,2 & 9,1 & 1,8 \\
\hline$\overline{\operatorname{Pr}>F}$ & 0,038 & 0,147 & 0,159 & 0,216 & 0,014 & 0,465 & 0,032 & 0,681 & 0,004 & 0,168 & 0,285 & 0,008 \\
\hline
\end{tabular}

em produção.

Em tomateiro irrigado por gotejamento foram encontradas raízes a uma profundidade de até $65 \mathrm{~cm}$, enquanto na aspersão a profundidade máxima foi de $55 \mathrm{~cm}$. Já o crescimento lateral das raízes no gotejamento foi menor que na aspersão. No perfil do solo até 20 $\mathrm{cm}$, por exemplo, foram encontradas raízes até $65 \mathrm{~cm}$ lateralmente à fileira de plantas, enquanto na aspersão as raízes cresceram até $85 \mathrm{~cm}$ (dados não apresentados). O maior crescimento lateral das raízes na aspersão deveu-se ao molhamento total da superfície, diferentemente do gotejamento que molhou cerca de $60 \%$ da área. No perfil total, estimou-se que o volume de solo explorado pelo sistema radicular do tomateiro irrigado por gotejamento foi $35 \%$ menor que na aspersão.

Não houve interação significativa ( $p>0,05)$ entre os fatores sistema de irrigação e sistema de cultivo para nenhuma das variáveis avaliadas, indicando resultados semelhantes de ambos os sistemas de irrigação nos sistemas de cultivos com e sem coentro. Também não foi verificado efeito significativo $(p>0,05)$ do sistema de cultivo sobre nenhuma das variáveis. Estudos de Medeiros et al. (2009) e Togni et al. (2009) mostraram que o consórcio tomate-coentro pode influenciar positivamente o manejo de T. absoluta e de B. tabaci ao afetar sua dinâmica populacional e reduzindo a densidade de insetos em sistemas convencionais e orgânicos de produção. No presente estudo, entretanto, o efeito do cultivo de coentro em consórcio não influenciou a produtividade do tomateiro. Por outro lado, os sistemas de irrigação avaliados tiveram efeito significativo sobre algumas variáveis de produção e de qualidade avaliadas, assim como sobre o índice de produtividade da água e as taxas de frutos podres e de morte de plantas (Tabela 1).

As produtividades total (média de 61,8 t ha-1) e comercializável (média de 41,1 t ha-1) não foram influenciadas significativamente $(\mathrm{p}>0,05)$ pelos tratamentos. Em média, 33,5\% da produção foram de frutos do tipo "refugo". Apesar de estar abaixo da média geralmente obtida em sistemas convencionais de produção, a produtividade comercializável obtida foi consideravelmente superior àquelas relatadas em sistemas orgânicos de produção por Menezes et al. (2007), Souza et al. (2007) e Schallenberger et al. (2008). Mesmo que Chartzoulakis \& Michelakis (1988) também não tenham observado variação da produtividade do tomateiro produzido sob diferentes sistemas de irrigação, os resultados aqui obtidos divergem da maioria dos estudos realizados em sistemas convencionais de produção, onde a produtividade de frutos é normalmente maior em cultivos irrigados por gotejamento (Nunes \& Leal, 2001; Marouelli et al., 2003).

Um dos fatores responsáveis por não ter havido diferenças de produtividade entre os sistemas de irrigação pode estar associado ao menor volume de solo explorado pelas raízes do tomateiro irrigado por gotejamento. Mesmo não se tendo constatado sintomas visuais de deficiência nutricional nas plantas, o menor crescimento radicular do tomateiro irrigado por gotejamento pode ter limitado a absorção de nutrientes e prejudicado o crescimento de plantas. Apesar de não avaliado, o menor crescimento das plantas no gotejamento foi visualmente perceptível. Segundo Carvalho et al. (2005) e Santos et al. (2008), a disponibilização de nutrientes pelo solo em sistemas orgânicos, devido à utilização de fertilizantes de baixa solubilidade, é lenta e gradativa. Adicionalmente, Phene et al. (1992) relatam que a utilização do sistema por gotejamento para a irrigação de tomateiro sem o uso da fertirrigação é ineficiente, resultando em pequeno incremento de produtividade devido ao menor volume de raízes. Assim, seria desejável que as raízes do tomateiro irrigado por gotejamento em sistema orgânico explorassem maior volume de solo.

Os tratamentos avaliados também não tiveram efeito significativo sobre a quantidade total de frutos (média de 44,2 frutos $/ \mathrm{m}^{2}$ ), nem sobre a quantidade de frutos comercializáveis (média de 24,8 frutos $/ \mathrm{m}^{2}$ ) produzidos por unidade de área. Por outro lado, a quantidade total de frutos e a quantidade de frutos comercializáveis por planta foram significantemente maiores nos tratamentos irrigados por aspersão (Tabela 1). Isso pode ser explicado, em parte, pela redução no estande de plantas de tomate nos tratamentos irrigados por aspersão, que foi em torno do dobro da observada no gotejamento (Tabela 1). A maior redução de estande na aspersão foi, aparentemente, devido à maior ocorrência de viroses (vira-cabeça e geminivírus) no tomateiro irrigado por aspersão.

Como a massa de frutos comercializáveis (média de 162 g) não foi influenciada significativamente pelos tratamentos, a maior taxa de plantas mortas na aspersão foi compensada por um aumento proporcional na quantidade de frutos por planta, de forma que a 
produtividade não foi alterada. Resultados semelhantes foram observados por Chartzoulakis \& Michelakis (1988) e Marouelli et al. (2003), que também não encontraram efeitos significativos de diferentes sistemas de irrigação sobre a massa de frutos.

A taxa de frutos podres na aspersão (média de 9,7\%) foi praticamente o dobro da verificada no gotejamento, que estava dentro da expectativa devido ao frequente molhamento da parte aérea do tomateiro. Possivelmente, o maior apodrecimento de frutos na aspersão foi favorecido pelos danos causados pela traça-do-tomateiro que, na presença de umidade, serviram de "porta de entrada" para fungos e bactérias. Em todas as colheitas realizadas não houve incidência de frutos com podridão apical nos tratamentos irrigados por aspersão e gotejamento. Este fato é um indicativo que as plantas não foram submetidas a condições de déficit hídrico ou de deficiência de cálcio (Lopes et al., 2006).

As taxas de frutos com danos por traça-do-tomateiro (média de 44,8\%) e por broca grande (média de 9,8\%) não foram afetadas pelos sistemas de irrigação avaliados. Verificou-se, no entanto, por meio de observação visual, que os danos pela T. absoluta à folhagem do tomateiro irrigado por gotejamento foram muito maiores que na aspersão. O fato do uso da irrigação por aspersão e do coentro em consórcio não terem apresentado efeito redutor nos danos causados pela traça-do-tomateiro aos frutos, diferentemente do relatado por Costa et al. (1998) e Medeiros et al. (2009), pode estar relacionado à elevada população de T. absoluta na área experimental, com taxas de danos próximas à $50 \%$ (Tabela 1 ), e ao comportamento do inseto adulto que, principalmente ao amanhecer e entardecer, voam e podem ter realizado a postura em parcelas adjacentes.

A severidade de oídio nos tratamentos irrigados por gotejamento foi expressivamente maior no gotejamento que na aspersão (Tabela 1), resultado que está em concordância com Lopes et al. (2006). Por outro lado, não foi verificada ocorrência de requeima (Phytophthora infestans), mesmo nos tratamentos em que as folhas do tomateiro eram mo- lhadas a cada irrigação. Destaca-se que durante a condução da cultura praticamente não houve formação de orvalho e a umidade relativa do ar durante a noite foi abaixo de $70 \%$. Outras doenças da parte aérea e de solo também não foram observadas durante o ciclo da cultura ou não ocorreram de forma expressiva.

A ocorrência conjunta e em níveis de severidade elevada de traça-do-tomateiro e, principalmente, de oídio nas plantas irrigadas por gotejamento (Tabela 1) acarretou danos consideráveis à folhagem do tomateiro, o que provavelmente reduziu de maneira considerável a taxa de fotossíntese das plantas e, consequentemente, limitou a produtividade de frutos.

Pode-se concluir que o cultivo de coentro consorciado com tomateiro não teve efeito significativo sobre as variáveis avaliadas. A produtividade e os danos por insetos aos frutos também não foram afetados pelos sistemas de irrigação, mas a ocorrência de frutos podres na aspersão foi o dobro do gotejamento. Plantas irrigadas por gotejamento tiveram redução na duração do ciclo, possivelmente devido ao menor volume de solo explorado pelas raízes e à maior severidade de danos causados pela traça-do-tomateiro e, principalmente, oídio. A quantidade de água fornecida ao tomateiro irrigado por gotejamento foi $20 \%$ menor que na aspersão.

\section{AGRADECIMENTOS}

Ao Centro de Desenvolvimento Tecnológico da Agricultura Orgânica do Distrito Federal (CDTOrg-DF), ao Conselho Nacional de Desenvolvimento Científico e Tecnológico (CNPq) e a Fundação de Apoio a Pesquisa do Distrito Federal (FAPDF) pelo apoio financeiro parcial na condução do trabalho.

\section{REFERÊNCIAS}

ALTIERI MA; SILVA EN; NICHOLS CI. 2003.O papel da biodiversidade no manejo de pragas. São Paulo: Editora Holos. 226p.

ATKINSON D; MACKIE-DAWSON LA. 1991. Root growth: methods of measurement. In: SMITH KA; MULLINS CE. Soil analysis. New York: Marcel Dekker. p.447-509.

BRASIL. 1995. Ministério da Agricultura, do
Abastecimento e da Reforma Agrária. Portaria $\mathrm{n}^{\circ} 553$ de 30 de agosto de 1995. Dispõe sobre a norma de identidade, qualidade, acondicionamento e embalagem do tomate in natura, para fins de comercialização e revoga as especificações de identidade, qualidade, acondicionamento e embalagem do tomate, estabelecidas pela Portaria $n^{\circ} .76$, de 25 de fevereiro de 1975. Diário Oficial da República Federativa do Brasil, Brasília.

CARVALHO AM; JUNQUEIRA AMR; VIEIRA JV; REIS A; SILVA JBC. 2005. Produtividade, florescimento prematuro e queima-das-folhas em cenoura cultivada em sistema orgânico e convencional. Horticultura Brasileira 23: 250-254.

CHARTZOULAKIS KS; MICHELAKIS NG. 1988. Influence of different irrigation systems on greenhouse tomatoes. Acta Horticulturae 228: 97-104.

COELHO MVS; CAFE FILHO AC; LOPES CA; MAROUELLI WA. 2000. Severidade de oídio em abóbora híbrida sob diferentes lâminas de irrigação e níveis de nitrogênio. Fitopatologia Brasileira 25: 157-160.

COLETTI C; TESTEZLAF R. 2003. O uso de água na tomaticultura. In: WORKSHOP TOMATE NA UNICAMP. Anais.... Campinas: Unicamp: Faculdade de Engenharia Agrícola (CD-ROM).

COSTA JS; JUNQUEIRA AMR; SILVA WLC; FRANÇA EH. 1998. Impacto da irrigação via pivô-central no controle da traça-do-tomateiro. Horticultura Brasileira 16: 19-23.

COUTO JR; RESENDE FV; SOUZA RB; SAMINEZ TCO. 2008. Instruções práticas para produção de composto orgânico em pequenas propriedades. Brasília: Embrapa Hortaliças. 8p. (Embrapa Hortaliças. Comunicado Técnico, 53).

LOPES CA; MAROUELLI WA; CAFÉ FILHO AC. 2006. Associação da irrigação com doenças de hortaliças. Revisão Anual de Patologia de Plantas 14: 151-179.

MAROUELLI WA; CALBO AG. 2009. Manejo de irrigação em hortaliças com sistema Irrigas ${ }^{\circledR}$. Brasília: Embrapa Hortaliças, 16p. (Circular Técnica, 69).

MAROUELLI WA; LOPES CA; SILVA WLC. 2005. Incidência de murcha-bacteriana em tomate para processamento industrial sob irrigação por gotejamento e aspersão. Horticultura Brasileira 23: 320-323.

MAROUELLI WA; SANT'ANA RR; SILVA WLC; MORETTI CL; VILELA NJ. 2003. Avaliação técnica e econômica do espaçamento de gotejadores em tomateiro para processamento cultivado em fileiras simples e duplas. Horticultura Brasileira 21: 202-206.

MAROUELLI WA; SILVA WLC. 2007. Water tension thresholds for processing tomatoes under drip irrigation in Central Brazil. Irrigation Science 25: 411-418.

MEDEIROS MA; SUJII ER; MORAIS HC. 2009. Effect of plant diversification on abundance of South American tomato pinworm and predators in two cropping systems. Horticultura Brasileira 27: 300-306.

MENEZES AH; PINHEIRO JCV; LIMA HJM. 2007. Rentabilidade mínima do tomate de 
mesa orgânico e sua competitividade em relação ao tomate convencional - Serra da Ibiapaba, Ceará. In: Congresso da Sociedade Brasileira de Economia, Administração e Sociologia Rural, 45. Anais... Londrina: SOBER (CD-ROM).

NUNES MUC; LEAL MLS. 2001. Efeitos da aplicação de biofertilizante e outros produtos químicos e biológicos, no controle da broca pequena do fruto e na produção do tomateiro tutorado em duas épocas de cultivo e dois sistemas de irrigação. Horticultura Brasileira 19: 53-59.

PHENE CJ; HUTMACKER RB; DAVIS KR. 1992. Two hundred tons per hectare of processing tomatoes - can we reach it? Hort Technology 2: 16-22.

PULUPOL LU; BEHBOUDIAN MH; FISHER KJ. 1996. Gowth, yield, and postharvest attributes of glasshouse tomatoes produced under deficit irrigation. HortScience 31: 926-929.

ROTEM J; PALTI J. 1969. Irrigation and plant diseases. Annual Review of Phytopathology 7: 267-288.

SANTOSFS; SOUZAPE; POZZAEA; MIRANDA JC; CARVALHO EA; FERNANDES LHM; POZZA AAA. 2008. Adubação orgânica, nutrição e progresso de cercosporiose $\mathrm{e}$ ferrugem-do-cafeeiro. Pesquisa Agropecuária Brasileira 43: 783-791.

SCHALLENBERGER E; REBELO JA; MAUCH CR; TERNES M; PEGORARO RA. 2008. Comportamento de plantas de tomateiros no sistema orgânico de produção em abrigos de cultivo com telas antiinsetos. Revista de Ciências Agroveterinárias 7: 23-29.

SOUZA JH; COSTA MSSM; COSTA LAM; MARINI D; CASTOLDI G; PIVETTA LA; PIVETTA LG. 2007. Produtividade de tomate em função da adubação orgânica e biodinâmica e da presença de cobertura de solo e de plantas companheiras. Revista Brasileira de Agroecologia 2: 842-845.

SOUZA JL. 2003. Tomateiro para mesa em sistema orgânico. Informe Agropecuário 24: 108-120.

TAMISIO LG. 2005. Desempenho de cultivares de tomate (Lycopersicon esculentum Mill) sob sistemas orgânicos em cultivo protegido. Piracicaba: USP-ESALQ. 87p (Tese mestrado).

TOGNI PHB; SUJII ER; MEDEIROS MA; FRIZZAS MR; ERDMAN M; CAVALCANTE KR; NAKASU EYT. 2009. Dinâmica populacional da mosca-branca em tomateiro sob monocultivo e consórcio, cultivo orgânico e convencional. Horticultura Brasileira 27: 179-184. 